\title{
Contribution of individual-based coupled physical-biological models to understanding recruitment in marine fish populations
}

\author{
Thomas J. Miller* \\ Chesapeake Biological Laboratory, University of Maryland Center for Environmental Science, PO Box 38, Solomons, \\ Maryland 20688, USA
}

\begin{abstract}
Annual publications involving the application of coupled physical-biological models for understanding fish recruitment processes have increased over the last decade. Sixty-nine papers were reviewed to assess the contribution these models have made to recruitment prediction and understanding. The majority of models reviewed were 2- and 3-dimensional numerical simulation models, although a limited number of 1-dimensional analytical models were included. Most models used a Lagrangian tracking algorithm to advect and diffuse particles within the model domain. The vertical and horizontal resolutions and temporal durations of the models varied widely. This review identified 3 categories of papers: explanatory, inferential and hypothesis generating. Reviewed papers were dominated by explanatory approaches. Assessment of the sensitivity of model predictions to the model parameters were rare, but not entirely absent in this group of papers. Inferential approaches were the next most common, and sought to infer the presence or role of a particular mechanism. Hypothesis-generating publications were the rarest, but perhaps have the most to contribute to a greater understanding of recruitment processes. An increase in the frequency of hypothesis-generating applications of coupled physical-biological models may be expected over time as the field matures and refinements to both the physical and biological processes included in the models are made.
\end{abstract}

KEY WORDS: Physical-biological models · Individual-based models · Recruitment · Fish populations · Feeding $\cdot$ Growth $\cdot$ Mortality $\cdot$ Behavior

Resale or republication not permitted without written consent of the publisher

\section{INTRODUCTION}

Since Hjort's (1914) seminal work, understanding the sources of variability in recruitment has been recognized as a central challenge of fisheries research. Understanding recruitment would benefit managers in establishing sustainable patterns of exploitation and provide fundamental insights into the regulation of fish populations generally (Hutchings 2000). Research conducted to date has documented the high and variable rates of mortality that characterize the early life histories of many fish (Houde 1989, Crowder et al. 1992). Changes in these rates are responsible for producing the wide variations in year classes observed in fish populations. Indeed, the principal challenge in pre- dicting recruitment is that only subtle changes in these mortality rates are needed to cause dramatic alterations in year class strengths.

Many hypotheses have been developed that seek to explain and predict the variability in recruitment in fish populations. These hypotheses may be grouped into 3 broad themes: food and growth-related, transport-related and predation-related hypotheses. Cowan \& Shaw (2002) and Govoni (2005) provide recent critical reviews of these ideas. Most of the hypotheses in these 3 categories invoke a physical context, thereby implying that understanding recruitment requires coupling physical and biological processes. However, as noted by Myers (1995), the relative coarseness of early biological and physical data prevented direct tests of 
hypotheses that invoked physical-biological interactions. Thus, initial efforts to understand the physical context in which biological processes occur were largely descriptive (Haury et al. 1978).

Developments over the last $25 \mathrm{yr}$ in both physical oceanography and fish ecology have increased our ability to formulate testable hypotheses regarding the role of physical processes and recruitment. In their review of the contribution of physical processes to fluctuations in marine fish populations, Werner \& Quinlan (2002) identified 3 important developments in physical oceanography that have advanced the coupling of physical and biological processes: the ability to collect synoptic data at appropriate spatial and temporal scales, improvements in the understanding of mesoscale ocean processes and the advent of powerful computational abilities. These advances allowed questions at scales appropriate to recruitment (i.e. on the order of 1 to $100 \mathrm{~km}$ and 1 to $90 \mathrm{~d}$ ) to be posed for the first time. Similar substantial changes in ecological studies of recruitment paralleled the changes in physical oceanography. In this context, the most notable of these was the rise of individual-based thinking in fish ecology (DeAngelis \& Gross 1992). This paradigm shift led researchers to ask not 'What is the mortality rate?' but rather 'What are the characteristics of the survivors?' (Crowder et al. 1992). Research findings led to the recognition that incorporation of individual variability into recruitment models is essential because survivors are not a random subset of the offspring. Differential offspring survival based on parental influences (Browman et al. 2006), spawning date (Rice et al. 1987), size and growth (Meekan \& Fortier 1996), and location (Thorrold et al. 2001) has been documented. Under conditions where individual characteristics vary and are subject to selective sources of mortality, forecasts based on the average are likely to be unreliable (Lomnicki 1992).

The advances in physical oceanography and fish ecology allowed the development of the first individual-level, coupled physical-biological models (ICPBM) of fish early life history in the late 1980s (Bartsch 1988, Bartsch et al. 1989). Others followed quickly, so that by 2001 Werner et al. (2001b) suggested spatially explicit ICPBMs had become the de facto tool for studies of fish recruitment. ICPBMs now play a central role in the majority of large-scale fisheries oceanography programs around the world, e.g. FOCI in Alaska (Megrey et al. 2002), various national GLOBEC programs (Hinrichsen et al. 2002, Lough et al. 2005) and the IDYLE program off South Africa (Mullon et al. 2003). Therefore, it is an appropriate time to assess the contribution of ICPBMs to knowledge of recruitment in fish.

The focus of this review is on the contribution of ICPBMs to improving understanding of recruitment processes in marine fishes. Accordingly, this review does not focus heavily on the physical models, but rather on the integration of the biology with the physics. Those interested in the physical models are referred to Haidvogel \& Beckman (1998). This review involved developing a simple classification of physical and biological processes and of scales used in each ICPBM. Based on this classification, I then identified commonalities among the reviewed papers with respect to the core processes of interest and the approach adopted. Finally, I assessed how these approaches affect the range of conclusions that can be drawn, and identified opportunities for future development.

\section{METHODS}

I reviewed the literature on the application of ICPBMs since 1989. The choice of 1989 was arbitrary, but was made to include the first broadly published example of the genre, that of Bartsch et al. (1989). The review was not an exhaustive list of contributions, but rather an unbiased sample of contributions selected to provide the foundation for a critical assessment of the different approaches that have been taken. Citations to be included in the review were selected in 2 phases. In the first phase, publications were identified using a keyword search of the ISI Web of Knowledge online database. Several search strings were used to identify likely publications. In the second phase of the literature search, I identified papers cited in or citing those publications identified in the first phase. In total, this process yielded 69 studies, published between 1989 and 2006. A full list of the citations is provided in Appendix 1 (available at: www.int-res.com/articles/suppl/m347 p127_app1.pdf) and the data extracted from each citation is provided in Appendix 2 (available at www.int-res.com/articles/suppl/m347p127_app2.xls).

All publications were categorized according to objective, approach, biological processes physical forcing and scale (Appendix 2). The physical models were identified with respect to the model framework, domain, horizontal and vertical resolution, temporal resolution, environmental forcing and the particle-tracking algorithm. The biological components of the model were identified as to the focal species, how the processes of feeding, growth and mortality were represented, behavioral representation and the tracking duration. Once these fundamental properties had been identified, the objective of each paper was classified as either: distribution, transport/retention, spawning-site selection, growth and survival, or feeding. These are hierarchical categories because, for example, all models involved questions of distribution. Thus, models focusing on growth and survival are a subset of models 
involving distribution. Similarly, most models of feeding were a subset of models of growth and survival. Finally, 3 categories of approach were recognized: explanatory, inferential and hypothesis generating. I characterized explanatory applications as those that sought to provide an explanation of an observed empirical pattern. Inferential approaches sought to quantify the relative contribution of different processes to producing the observed pattern, and had to include simulation with different levels of biological or physical factors. Hypothesis-generating approaches were those that led to hypotheses that could be tested either within the model itself or by independent empirical observations. A full listing of the data extracted from the review is provided in Appendix 2.

\section{RESULTS}

The literature review documented the increase in the use of ICPBMs in studies of fish recruitment since 1989 (Fig. 1). Not surprisingly, although ICPBMs have been developed for a range of different ecosystems, application of these models has been concentrated in areas that support industrialized fisheries: the Northeast Atlantic shelf, the Northwest Atlantic shelf and the Alaskan shelf (Table 1). Together, these 3 regions accounted for almost three-quarters of the reviewed papers. The majority of the remaining areas are mid- to high-latitude systems: only 3 studies involved tropical or subtropical systems.

\section{Hydrodynamic modeling}

Hydrodynamic processes have been represented in several different ways in ICPBMs (Appendix 2). The majority of the hydrodynamic models were 3-dimensional, numerical simulation models that represent the domain of interest as a series of discrete, small spatial elements. The numerical simulation models differed principally in the algorithm used to solve the hydrosta-

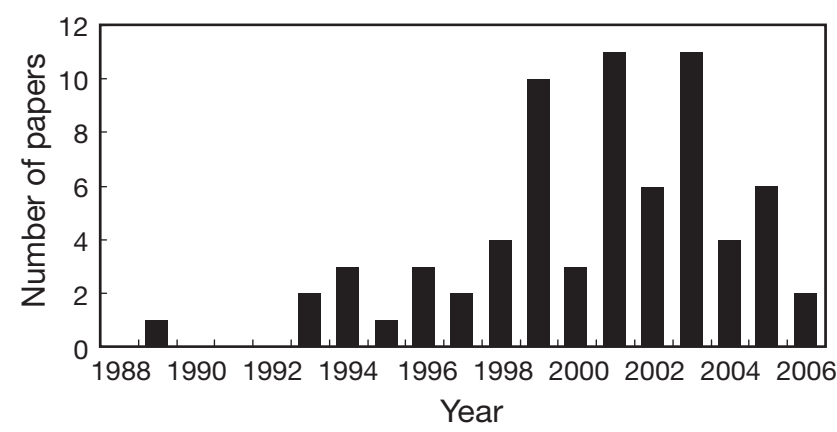

Fig. 1. Publication year of papers included in the review (listed in Appendix 1)
Table 1. Distribution of reviewed individual-level, coupled physical-biological models (ICPBM) by ocean region

\begin{tabular}{|ll|}
\hline Ocean region & Number of studies \\
\hline NE Atlantic shelf (including North Sea, & 27 \\
Baltic Sea and Bay of Biscay) & \\
NW Atlantic shelf (including Georges & 17 \\
Bank, Grand Banks and Scotian Shelf) & \\
NE Pacific (including Alaskan shelf) & 6 \\
Western Atlantic shelf & 6 \\
SE Atlantic & 5 \\
NW Pacific & 2 \\
SW Pacific & 2 \\
W Pacific & 1 \\
Caribbean & 2 \\
Gulf of Mexico & 1 \\
\hline
\end{tabular}

tic primitive equations (finite difference vs. finite element) and in how the spatial elements were defined. Many of the early models were based on Geophysical Fluid Dynamics Laboratory modular ocean models (Bryan 1969, Cox 1984) that use the finite difference algorithm and fixed depth levels. A popular early implementation of this code was the Hamburg Shelf Ocean Model (HAMSOM), which has been parameterized for several different spatial domains (Bartsch \& Coombs 1997, Gallego et al. 1999, Hislop et al. 2001, Hao et al. 2003). This modeling approach continues to see use, most recently in a series of papers by Hinrichsen and colleagues (Voss et al. 1999, Hinrichsen et al. 2001, 2002, 2003a,b, 2005, Koster et al. 2001). As a result of the use of fixed depth levels in these models, particular care has to be taken in matching the depth layers selected with the bathymetry. One approach to overcoming this challenge has been to use a terrainfollowing coordinate system in which depth is represented as a percentage of the total water column depth at any point. Such terrain-following, primitive equation models were also common in the review (Hinckley et al. 1996, 2001, Sæetre et al. 2002, Adlandsvik et al. 2004). Most recently, this terrain-following scheme has been implemented in the Regional Ocean Model System (ROMS), for which applications have been increasing (Mullon et al. 2002, Huggett et al. 2003, Vikebo et al. 2005). Models that represent depth indirectly as isopycnals (constant density surfaces) have also been used (Paris et al. 2005, Cowen et al. 2006), although these were less common. The other principal 3-dimensional numerical simulation models were ones that used a finite element (FEM) algorithm rather than the finite difference scheme. These FEM models share a common heritage (Lynch et al. 1996), and have been implemented for the Northwest Atlantic shelf (Werner et al. 1994, Lough et al. 2005) and the mid-Atlantic Bight (Quinlan et al. 1999, Stegmann et al. 1999). A small number of ICPBMs that did not use numerical 
simulation models as their foundation were identified in the review. These approaches include coarser scale box-models (Maes et al. 2005) or data-driven frameworks (Heath et al. 1998, Reiss et al. 2000, Helbig \& Pepin 2002).

The spatial and temporal scales of the hydrographic models varied over several orders of magnitude (Appendix 2). The spatial scale of the model is critical to its ability to resolve features that may play important roles in the ecology of larval fish (Helbig \& Pepin 2002). The finest horizontal resolution reported was $0.005 \mathrm{~km}$ (Brown et al. 2004), the coarsest $150 \mathrm{~km}$ (Suda \& Kishida 2003). The distribution of horizontal resolutions was multimodal, likely reflecting the heritage of different hydrographic models rather than 'choices' by researchers of the resolution that was most appropriate for the question being studied. Surprisingly, there was no trend for models to become more highly resolved over time. The vertical resolution of models was much finer than their horizontal resolution, but also varied considerably. Determination of the finest vertical resolution used was problematical in S-coordinate models, which report the layers with regard to the fraction of the total water column. However, it is likely that the minimum vertical resolution was on the order of $1 \mathrm{~m}$ (North et al. 2005).

Several time scales can be identified to characterize hydrodynamic models. The numerical simulation models often used complex, time-stepping algorithms to ensure solution stability. However, for many models it was possible to determine a temporal resolution at which flow fields were estimated. Time steps varied widely from seconds (North et al. 2005) to on the order of an hour. In contrast to the numerical simulations, the simpler box model and matrix projection approaches (Suda \& Kishida 2003, Maes et al. 2005) often had daily time steps. The other temporal scale of importance is the time scale at which environmental forcing was applied in the model. These time scales varied from hourly to daily (Appendix 2). Models were forced by a variety of environmental forcing functions (Appendix 2). The majority of models included forcing from M2 tides, wind stress and inflow. In many cases, models were driven by synoptic data from the model domain collected for the time period modeled; in other cases, climatological forcing was employed.

\section{Coupling hydrodynamics and biology}

Although described as coupled physical-biological models, the coupling of numerical simulation models was typically offline rather than in real time for computational reasons (see Hinckley et al. 1996 for a comparison of different coupling schemes). In this scheme, runs of the hydrodynamic model are completed and output is stored at set intervals. The stored flow fields are then used by the individual-based biological model to move and track individual eggs and larvae throughout the model domain. The adequacy of these particletracking algorithms is at the heart of the reliability of forecasts from ICPBMs. The principal challenge to these particle-tracking algorithms is to provide subgrid-scale resolution of fluid flows, as the horizontal and vertical spatial resolution of the hydrodynamic models (discussed above) are several orders of magnitude larger than the length scales of typical larvae (3 to $10 \mathrm{~mm}$ ). This mismatch of scales challenges modelers in capturing small-scale features of the flow critical to larval behavior (Fiksen \& MacKenzie 2002) or egg and larval distributions (Helbig \& Pepin 2002). Because of stochasticity at subgrid scales, there is an ensemble of trajectories for each starting location. Early models used a simple scheme that updates the position of tracked particles based on spatially interpolated model velocities with small random components (Bartsch \& Knust 1994). As the field has developed, the particletracking algorithms have become more sophisticated, with increasing attention being paid to the statistical aspects of subgrid-scale motion (Heath et al. 1998). Even when the model incorporates the correct statistical distribution of subgrid-scale motion, proper interpretation of the distribution of trajectories of individual larvae remains challenging (Brickman \& Smith 2002).

As a result of uncertainties in the forecasted trajectories, the duration over which early life stages are tracked was an important feature of the models. Here, models diverged markedly owing to their differing objectives. For example, Fiksen \& MacKenzie (2002) followed the fates of individual larvae for only $1 \mathrm{~d}$ in their work to explore the processes regulating feeding ecology of Atlantic cod Gadus morhua (hereafter 'cod') on Georges Bank. In contrast, several authors ran their hydrodynamic model over multiple years. In particular, Cowen et al. (2006) tracked the fates of larval reef fishes in the Caribbean produced by sequential monthly spawnings over a $5 \mathrm{yr}$ period to estimate the connectivity among local populations on different island reef systems. However, the majority of tracking durations were for periods of $<120 \mathrm{~d}$, a time frame typical for early life-history stages of many species to carry out transition from plankton to nektonic or demersal habits.

\section{Biological modeling}

Taxonomically, the papers in the review were dominated by commercially important gadoid species (Fig. 2, Appendix 2). Studies of cod, haddock 


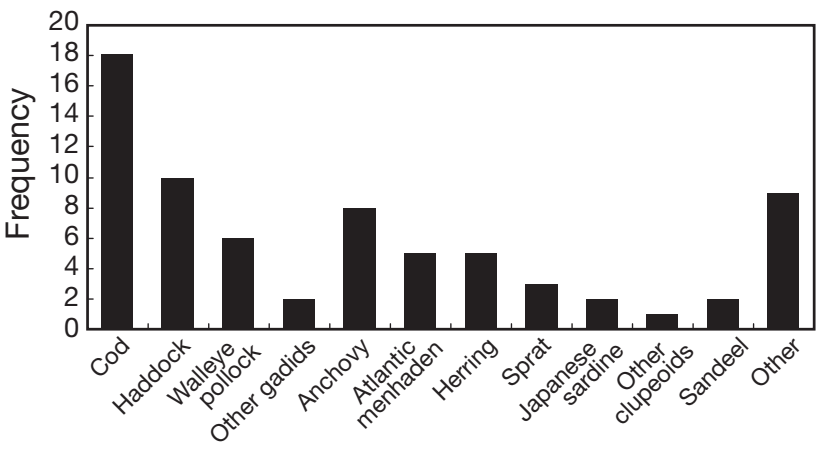

Fig. 2. Taxonomic distribution of species studied in reviewed models (listed in Appendix 2)

Melanogrammus aeglefinus and walleye pollack Theragra chalcogramma accounted for almost half (34) of the reviewed publications. The focus on these species reflects management interests rather than that these species are necessarily representative of ecological processes occurring in a broad class of species.

Biological representation within the model was characterized to assess the ability of the model to test the feeding-, transport- and predation-related recruitment hypotheses described above (Table 2). Not all models included feeding or growth processes. Approximately one-fifth $(20.6 \%)$ of reviewed papers included feeding as a process within the individual-based model (IBM). All feeding routines included prey selection to some extent. Some models included a highly detailed and mechanistic description of feeding (Megrey \& Hinckley 2001, Fiksen \& MacKenzie 2002, Hinrichsen et al. 2003b, Lough et al. 2005). For example, Fiksen \& MacKenzie (2002) developed a highly detailed model of the feeding process that modeled prey encounter and capture as explicit functions of light, turbulence, prey size and vagility, and of larval feeding behavior. Other representations of the feeding process were coarser. For example, Werner et al. (1996) used empirical relationships (Laurence 1978) to drive search and ingestion in their IBM. While almost a quarter of all reviewed papers included a process-level description of feeding, only approximately one-half of these

Table 2. Distribution of representation of biological processes in ICPBMs. Note that proportions do not sum to 1 because multiple processes are represented in individual models

\begin{tabular}{|lc|}
\hline Process & Proportion \\
\hline Feeding & 0.206 \\
Prey selection & 0.188 \\
Prey dynamics & 0.101 \\
Age & 0.838 \\
Growth & 0.367 \\
Mortality & 0.308 \\
Behavior & 0.433 \\
\hline
\end{tabular}

papers included any dynamics in the prey community. As with the feeding process itself, how prey dynamics were modeled varied. For example, Bartsch \& Combs (2004) used satellite-derived sea-surface temperature and chlorophyll fields to model the abundance of Calanus and Acartia, principal prey for larval mackerel Scomber scrombrus. Other researchers based the prey field on data interpolated from field collections (Lough et al. 2005).

Growth is an emergent property of bioenergetic processes that is expressed in changes in size at age. Given the central role of size-dependent processes in fish early life history, it was anticipated that growth would be a common feature of ICPBMs. Yet only $36.7 \%$ of all reviewed studies included a growth component (Table 2). Two broad approaches to modeling growth were evident. In one approach growth was forecast based on the temperature field predicted by the hydrographic model (Heath \& Gallego 1997, 1998, Brickman \& Frank 2000). Alternatively, growth was modeled mechanistically with surplus energy from feeding (after meeting metabolic requirements) being allocated to growth (Werner et al. 1996, 2001a, Hinckley et al. 2001). Bartsch \& Coombs (2004) employed an empirical growth model that was both temperature and food dependent.

All models reviewed were spatially specific, either implicitly or explicitly, and thus all dealt with the transport, retention, or distribution of eggs and larvae to some degree. Of the 69 reviewed papers, 10 were implicitly spatial and did not determine the precise location of early life stages in the model domain. These papers did not seek to explicitly test transport-related hypotheses. Rather, these papers dealt with issues of habitat selection (Lough \& Manning 2001, Suda \& Kishida 2003, Maes et al. 2005). In contrast the 59 other papers explicitly studied the consequences of transport of the early life-history stages of fish. These papers sought to explain or understand the role of transport and/or the retention of early life stages from spawning sites or to nursery grounds (Berntsen et al. 1994, Shackell et al. 1999, Reiss et al. 2000, Mullon et al. 2002, Hinrichsen et al. 2003b). Larval behavior can have a significant impact on their subsequent locations. Accordingly, $43.3 \%$ of the reviewed papers included some degree of larval behavior. The most common behavior included in models was age-dependent vertical migration (Heath et al. 1998, Hinckley et al. 2001, Adlandsvik et al. 2004). Light was also commonly used as a behavioral cue for vertical migration (Bartsch \& Knust 1994, Pedersen et al. 2003, Hinrichsen et al. 2005).

The final class of hypotheses relating to fish recruitment invoke predation of eggs and larvae as a principal agent. Only $30.8 \%$ of the reviewed studies 
included any egg or larval mortality in their formulations (Table 2). Of the 22 papers that included mortality, 8 considered only starvation mortality and not predation mortality directly (Werner et al. 1993, 2001a, Hinckley et al. 1996, 2001, Hinrichsen et al. 2002, $2003 \mathrm{~b})$. Of the others, the majority of models used general temperature-dependent (Mullon et al. 2002, 2003) or weight-dependent (Heath \& Gallego 1998, Brickman \& Frank 2000, Brickman et al. 2001) empirical relationships to represent mortality. Only Maes et al. (2005) included a dynamic predator-prey relationship; they were able to do so because they used a boxmodeling approach rather than a detailed hydrodynamic model.

\section{Model applications}

In reviewing published papers for this review, 3 categories of application of ICPBMs could be recognized: explanatory, inferential and hypothesis generating (Table 3). In the section that follows, I identify the characteristics of each approach and review a limited number of examples of each.

Explanatory applications of ICPBMs were the first to appear in the literature. Fifty-eight percent of reviewed papers was deemed to be explanatory in nature. In explanatory applications, researchers sought to explain observed patterns in the spatial arrangement of the early life stages of fish. However, the comparison between observed patterns and those predicted by the models was at most qualitative in nature and rarely involved an assessment of the sensitivity of predictions to parameter values. Werner et al.'s (1993) groundbreaking work on the transport of cod and haddock 'eggs' on Georges Bank is a clear example of this approach. Werner et al. (1993) used a finite element model with an adaptive mesh to model springtime flows on Georges Bank. Coupling of physical and biological models occurred offline, with the calculated flow fields for the entire tracking period serving as inputs to an IBM. Within the IBM, passive particles representing cod and haddock eggs were released at known spawning times at depths of 1,30 , or $50 \mathrm{~m}$ and tracked using a Lagrangian stochastic particle-tracking model. Inclusion of vertical migration behavior de-

Table 3. Proportion of approaches in the application of ICPBMs to studies of fish early life history

\begin{tabular}{lc|}
\hline Approach & Proportion \\
\hline Explanatory & 0.579 \\
Inferential & 0.304 \\
Hypothesis-generating & 0.116 \\
\hline
\end{tabular}

creased the probability of retention. The results from the ICPBM clearly indicated that only eggs released at $50 \mathrm{~m}$ were retained on the bank and completed a movement onto the northwest flank of the bank $90 \mathrm{~d}$ after release. In a second explanatory application, Voss et al. (1999) used an ICPBM to explain movement of cod larvae between ichthyoplankton surveys. They used a fixed-layer, finite-difference model with 28 depth levels and an approximately $5 \mathrm{~km}$ horizontal resolution to reproduce the hydrography of the Baltic Sea. Virtual cod larvae were released in a pattern that represented the distribution of cod larvae observed in the southern Baltic in August 1991, based on ichthyoplankton sampling. The particles in the model were tracked for $21 \mathrm{~d}$, and then the distribution of cod predicted by the model was qualitatively compared to that observed during a second ichthyoplankton survey. Voss et al. concluded that drift simulations explained the change in distributions observed between the 2 survey dates. Explanatory ICPBMs have played an important role in furthering our understanding of retention and transport in the early life histories of fish. But it is important to note that the agreement between observed and predicted data does not imply that the mechanisms operating in the model are equivalent to those operating in the field.

A second category of application employs ICPBM to infer the importance of particular processes or mechanisms. By this very definition, the approach compares alternative scenarios or parameter sets to determine which is more likely to occur in nature. This is a more powerful application of models and lends itself to hypothesis testing. Thirty percent of reviewed papers adopted an inferential approach. In one example, Brickman \& Frank (2000) compared predictions of 2 alternative mortality models on the distribution, development and abundance of haddock cohorts in the Browns Bank-Bay of Fundy region off Nova Scotia, Canada. Hydrography in the model was predicted by a 3-dimensional, finite-element QUODDY model. Coupling the flow field produced by the hydrodynamic model and the individual-based biological model was achieved using a Lagrangian stochastic particletracking algorithm, Brickman \& Frank (2000) compared the results of integrated and stage-specific mortality schemes in the IBM. By comparing modal characteristics of predicted and observed cohorts, they concluded that a stage-based mortality model was required to accurately represent cohort dynamics and recruitment. In a second example of an inferential application of an ICPBM, Fiksen \& MacKenzie (2002) implemented a biological IBM with readily interpretable biological parameters within the flow fields calculated by the 3-dimensional FEM of Georges Bank used by Werner et al. (2001a). Fiksen \& MacKenzie 
(2002) contrasted the implications of different feeding models. They concluded that the different feeding models yielded different predictions regarding prey selectivity and the conditions under which larval cod experience prey limitation.

The final application category of ICPBMs was the rarest, but is perhaps the one that has the most to contribute to understanding recruitment. In these applications, ICPBMs were used to develop testable hypotheses that could be investigated either within an ICPBM framework or with independent, empirical data. Only $11 \%$ of reviewed papers adopted this approach. Two examples suffice to illustrate the power of the approach. Mullon et al. (2002) used an ICPBM to test hypotheses regarding the evolution of spawning sites and periods for anchovy Engraulis capensis. They implemented a 3-dimensional ROMS model of the Benguela ecosystem to generate climatological flow fields. The flow fields served as inputs to an IBM that tracked the trajectories of egg and larval anchovy. Lagrangian stochastic tracking generated differences among the trajectories followed by different cohorts of larvae. Mullon et al. (2002) postulated a simple evolutionary rule that larvae that successfully reached the known nursery area demonstrated natal fidelity, returning to their own spawning location to reproduce. To test hypotheses as to why observed spawning locations had become favored, Mullon et al. (2002) defined recruitment 'success' such that larvae could not be advected offshore, had to reach the nursery area within 30 to $60 \mathrm{~d}$ and could not have experienced temperatures $<14^{\circ} \mathrm{C}$. Larvae that successfully reached known nursery areas followed a simple rule of natal site fidelity in selecting where to spawn. Mullon et al. (2002) then quantified the 'evolution' of spawning sites over 60 generations. They found that only advection and temperature constraints were required to yield a strong convergence of observed and predicted spawning locations and dates. A second example of the hypothesis-generating application of ICPBMs demonstrates how such models could be used to generate hypotheses that could be tested external to the model. Quinlan et al. (1999) used an ICPBM to identify potential spawning sites of Atlantic menhaden Brevoortia tyrannus that recruit to estuarine nursery areas along the US mid-Atlantic Bight. They predicted that recruits to 3 potential nursery areas (Delaware Bay, Folly Inlet and Chesapeake Bay), but spawned in the same location, should differ in age at entry to the nursery by specific amounts. Alternatively, individuals that recruit to the 3 different nursery areas at the same age on the same day should be drawn from different spawning locations. These hypotheses are currently being tested using otolith microchemical and birthdate frequency analysis of recruits to 2 of the 3 nursery areas.

\section{DISCUSSION}

ICPBMs have contributed significantly to our understanding of recruitment processes in marine fish populations, particularly with regard to transport and retention. Their application has evolved rapidly over the past quarter of a century. Initially, development of a numerically stable, highly parameterized model that could reproduce patterns in the distribution and characteristics of the early life-history stages of fish was in itself a significant achievement. More recently, these models have become increasingly more spatially resolved and have included more biological detail. In parallel with increases in model sophistication there has been a change in the use of ICPBMs from a largely explanatory role to one of hypothesis generation. These developments of ICPBMs in fisheries have paralleled changes in the development and use of models in other ecological fields (Kingsland 1985). For example, Gentleman (2002) suggested that models of plankton dynamics evolved from descriptive to hypothesis-testing tools between the 1940s and the turn of the century. Not surprisingly, this field also experienced the development of coupled physicalbiological models (Capella et al. 1992) and Lagrangian tracking algorithms (Ishizaka \& Hofman 1988). The success of models in other ecological fields suggests cause for optimism for the future of ICPBMs in studies of fish recruitment.

ICPBMs show great potential benefit in understanding recruitment, because they inherently involve variation induced by local interactions between individuals and their resources, a key justification for individualbased approaches in ecology (Grimm \& Railsback 2005). Transport-related recruitment hypotheses clearly meet this criterion. Individual eggs and larvae have different experiences and fates because they follow different spatial trajectories (Heath \& Gallego 1997). Thus, addressing transport-related hypotheses requires individual-based approaches, whether in modeling or field studies. ICPBMs have allowed researchers to identify potential spawning locations (Quinlan et al. 1999, Bruce et al. 2001), quantify patterns of retention within spawning locations (Werner et al. 1993, Hermann et al. 1996, Brickman et al. 2001, Stenevik et al. 2003) and transport from spawning locations to potential nursery areas (Heath \& Gallego 1998, Allain et al. 2001, Adlandsvik et al. 2004, Brown et al. 2004) for specific systems. Despite the success of ICPBMs in generating patterns similar to those observed in individual systems, these models have yet to be used to conduct strong tests of individual recruitment hypotheses, largely because of ongoing challenges related to the number of and duration over which individuals can be tracked and the need to close the life cycle. Few 
of the 69 papers reviewed included spawning dynamics, and only 5 were multigenerational. Not surprisingly, all of these multigenerational models were either inferential or hypothesis generating. However, none specifically tested classical hypotheses related to the determination of year class strength. If ICPBMs are to be used to test such hypotheses, it is critical that they are developed as a part of whole life cycle models as has been accomplished by Rose and colleagues in the ecological literature using either solely IBMs (Rose et al. 1999b) or IBMs as a component in a nested modeling approach (Rose et al. 2003). Development of a nested modeling approach to addressing biological oceanographic questions generally would likely be most effective for recruitment questions (deYoung et al. 2004).

However, it is important to note that the reliability of findings from these models relies on the accuracy of the hydrographic model and the adequacy of the tracking algorithms. Recently, Friedrichs et al. (2006) have highlighted concerns regarding the impact of alternative hydrodynamic models on forecasts from coupled physical-biological models at the ecosystem scale. While impacts of alternative hydrodynamic models on the forecasts at this scale may be expected, because the models are often coupled in real time, rather than offline as is more common for early life history ICPBMs, there was no indication in the literature that such impacts have been considered.

Particle-tracking schemes have also received considerable attention. Brickman \& Smith (2002) identify 2 concerns relating to particle tracking, which they term underseeding problems. Both concerns relate to the number of particles that must be tracked. The first concern is that sufficient particles must be tracked so that their ensemble average accurately (and hopefully precisely) reflects the true underlying distribution of the transport process. The second concern relates to the probability of detecting rare events in a stochastic process. Brickman \& Smith (2002) discuss both problems in terms of the relative size of the spawning and nursery areas. If spawning and nursery areas are coincident and large, then only a small number of particles and a few simulations may be needed, because we are trying to estimate the average of a process. In contrast, if the spawning area is large and the nursery area is small, considerably more particles and a large number of simulations may be needed, because we are trying to estimate the rare event of reaching the nursery area. Brickman \& Smith (2002) suggest tests that could be used to determine the adequacy of the number of particles and trials used. Few researchers appear to have considered this aspect of ICPBMs, and it deserves more attention.

To the extent that food-related and predationrelated hypotheses rely on spatially generated differ- ences, addressing these 2 questions may require individual-level approaches. ICPBMs induce variability in growth from spatially explicit differences induced by temperature (Heath \& Gallego 1998, Brickman \& Frank 2000) or the prey field exploited (Werner et al. 1995, Lough et al. 2005). However, the majority of ICPBMs have assumed that this is the only source of individual variability. Yet variation can arise from other processes. For example, there are likely inherent differences among larvae that will produce different growth patterns even under identical environmental conditions. In the presence of size-dependent sources of mortality, common in early life history (Miller et al. 1988), this inherent inter-individual variability can have important consequences (Rice et al. 1993). Although this is widely appreciated in IBMs developed in the field of fish ecology (DeAngelis et al. 1980, Cowan et al. 1993, Rice et al. 1993, Rose \& Cowan 1993, Cowan et al. 1996, Letcher et al. 1996, Rose et al. 1999a), variation of this sort is much less frequently evident in ICPBMs (Hinckley et al. 1996). This omission may be particularly important as it is likely that recruitment is not regulated by a single mechanism, but rather results from the interaction of multiple mechanisms (Crowder et al. 1992, Cowan \& Shaw 2002). Accordingly, not including inter-individual variability in vital rates may limit the utility of ICPBMs to address recruitment hypotheses other than transportrelated ones. The consequences of this assumption must be assessed.

There have been 2 different approaches to exploring feeding and growth-related recruitment hypotheses in ICPBMs. One approach uses the temperature field predicted from the hydrographic model to predict growth. This approach is motivated by concerns over the accuracy of the representation of subgrid-scale processes in the hydrographic model. The conservative nature of temperature means that it is less sensitive to subgridscale concerns. The approach also has the advantage that there is no need to model prey populations. However, there are also potential pitfalls to this approach if the underlying temperature-dependent growth model is incorrectly parameterized, or applied to a population for which it was not developed (Folkvord 2005). The approach also implicitly assumes that there is no restriction on food-dependent growth variation. The alternative approach is to specifically model consumption and bioenergetic processes. This has the advantage of directly linking the prey field and environment to forecasted growth, a central feature of many feedingrelated recruitment hypotheses (MacKenzie et al. 1994). This approach has been used to infer the importance of small-scale turbulence on larval feeding (Werner et al. 2001a) and the potential for prey limitation (Fiksen \& MacKenzie 2002). However, the pro- 
cess-level approach also faces significant challenges. The approach relies on extending hydrographic forecasts to subgrid scales that are perhaps 2 to 4 orders of magnitude smaller than the minimum horizontal resolution of the models. Even were this not a concern, encounter processes between planktonic predators and prey are generally not well understood, and are a focus of considerable research (Visser \& Kiorboe 2006). However, inferential approaches can be used to select among alternative parameterizations (Megrey \& Hinckley 2001, Fiksen \& MacKenzie 2002, Lough et al. 2005). Thus, the application of process-specific ICBPMs may help inform our understanding of the importance of individual steps in the feeding cycle on recruitment.

Predation-related recruitment hypotheses have received little attention within an ICPBM framework (Maes et al. 2005). Two reasons likely account for the lack of attention. First, potential predators are highly vagile and their distribution and behavior is not driven by hydrography. In a hydrodynamic context, predators represent the crossing streamlines problem. However, this should not be a barrier to the inclusion of predators in ICPBMs. Predators have been included in spatially explicit IBMs in the ecological field (Rose et al. 1999b). Inclusion of predation will require consideration of whether and how potential predators respond to the distribution of the eggs and larvae modeled in the ICPBM and may require inclusion of alternative prey. Coupled NPZ-ICPBMs that include multiple trophic levels have already been developed (Hermann et al. 2001), suggesting that it is possible. Coupling of additional trophic levels to such models, while undoubtedly difficult, will be required if predation-related hypotheses are to be considered. The second barrier to inclusion of predation, or any mortality source, in ICPBMs has been concerns over the number of particles that must be tracked. Super-individual approaches (Scheffer et al. 1995) are one approach to overcoming this concern. Although widely used in ecological IBMs (Bunnell \& Miller 2005), super-individuals have seen little use in ICPBMs (Hinckley et al. 1996, Bartsch \& Coombs 2004, Bartsch et al. 2004). This approach allows individual particles in a model to represent a large number of individual organisms. While there are challenges to how variability is represented within the super-individual, this approach does permit a realistic population of potential recruits to be followed.

One reason that individual-based approaches have been successful in fish ecology has been the adoption of the 'characteristics of the survivors' approach, which relies on successive comparison of survivors with the distribution from which they were drawn (Meekan \& Fortier 1996). Use of ICPBMs in hindcasting mode has been effective in determining potential spawning sites
(Quinlan et al. 1999, Hislop et al. 2001). However, the hindcasting approach offers the potential to circumvent the challenge of incorporating mortality discussed above, because by definition those individuals that have reached a nursery ground are survivors. There are certainly limitations on when a hindcasting approach can be used in ICPBMs. For example, hindcasting trajectories of survivors will not result in a single-source location, but rather will generate a probability distribution of possible locations. This approach will lead to the development of a specific hypothesis that could then be tested in either other forward-projecting ICPBMs or with independent, empirical data.

Although not a focus of this review, the reliability of hydrodynamic models should not ignored. It is important that the model resolves the physical processes at a sufficient scale to allow pertinent physical and biological processes to be expressed. In particular, the biological processes of interest likely occur at scales many times smaller than the resolution of the physical model. Larval behaviors, which have been shown to have important ramifications on the distributions and fates of larvae in ICPBMs (Hare et al. 1999), all occur on subgrid scales. Indeed the behaviors and cues that elicit them are generally poorly understood for fish larvae (Weissburg \& Browman 2005). Generally, the data that are available are from highly artificial laboratory experiments, which may not be relevant to field conditions. Even the extent to which physical processes are resolved may be problematical. For example Helbig \& Pepin (2002) resampled high-frequency radar data at different scales to force an advection-diffusion model of Conception Bay, Newfoundland. Helbig and Pepin were interested in the effects of the temporal and spatial resolution of the hydrographic model on the prediction distribution of fish eggs. They found that significant deviations between observed and predicted distributions occurred at model resolutions as low as $3 \mathrm{~km}$. Their results suggest that even sophisticated hydrographic models may not sufficiently resolve physical processes to permit accurate forecasts of ichthyoplanktonic distributions, yet the principal use to date of ICPBMs is in addressing transport-related hypotheses.

In summary, ICPBMs are maturing and will continue to be an important tool in furthering our understanding of recruitment. If they are to fulfill this potential, several trends should be encouraged. We should also encourage an expansion of focus from questions of distribution and transport toward strong tests of specific recruitment hypotheses. This can be helped by development of ICPBMs for different systems that use the same model structure. There should also be an evaluation of whether the failure to include sources of individual variation other than spatially induced ones 
biase the forecasts of ICPBMs. This question can most easily be addressed by encouraging the adoption of inferential and hypothesis-generating approaches. The time for using ICPBMs to describe a single realization of a recruitment event is past. There should be increased attention on the impacts of uncertainty in parameter estimates on model predictions. This uncertainty can be addressed by using experimental design tools to structure ICPBM simulations (Hinckley et al. 2001) and to guide analysis of the rich and complex results these models produce. Only when ICPBMs are used as inferential or hypothesis-generating platforms and when parameter uncertainty is specified and accounted for fully will ICPBMs be able to provide the strong tests of hypotheses relating to recruitment mechanisms of which they are capable.

Acknowledgements. The author thanks the conveners for the invitation to participate in and support for attending the conference. The ideas expressed herein are my own, but they have benefited from discussions with many people. I thank in particular J. Dower, A. Folkvord, B. Leggett, B. MacKenzie, P. Pepin, J. Rice, K. Rose and C. Werner. This work was supported in part by a grant from the NOAA Chesapeake Bay Office (NA05NMF4571257). This is contribution number 4082 of the University of Maryland Center for Environmental Science Chesapeake Biological Laboratory.

\section{LITERATURE CITED}

Adlandsvik B, Gundersen AC, Nedreaas KH, Stene A, Albert OT (2004) Modelling the advection and diffusion of eggs and larvae of Greenland halibut (Reinhardtius hippoglossoides) in the north-east Arctic. Fish Oceanogr 13:403-415

Allain G, Petitgas P, Lazure P (2001) The influence of mesoscale ocean processes on anchovy (Engraulis encrasicolus) recruitment in the Bay of Biscay estimated with a three-dimensional hydrodynamic mode. Fish Oceanogr 10:151-163

Bartsch J (1988) Numerical simulation of the advection of vertically migrating herring larvae in the North Sea. Meeresforschung 32:30-45

Bartsch J, Coombs S (1997) A numerical model of the dispersion of blue whiting larvae, Micromesistius poutassou (Risso), in the eastern North Atlantic. Fish Oceanogr 6:141-154

Bartsch J, Coombs SH (2004) An individual-based model of the early life history of mackerel (Scomber scombrus) in the eastern North Atlantic, simulating transport, growth and mortality. Fish Oceanogr 13:365-379

Bartsch J, Knust R (1994) Simulating the dispersion of vertically migrating sprat larvae (Sprattus sprattus (L.)) in the German Bight with a circulation and transport model system. Fish Oceanogr 3:92-105

Bartsch J, Brander K, Heath M, Munk P, Richardson K, Svendsen E (1989) Modeling the advection of herring larvae in the North Sea. Nature 340:632-636

Bartsch J, Reid D, Coombs SH (2004) Simulation of mackerel (Scomber scombrus) recruitment with an individual-based model and comparison with field data. Fish Oceanogr 13:380-391

Berntsen J, Skagen DW, Svendsen E (1994) Modelling the transport of particles in the North Sea with reference to sandeel larvae. Fish Oceanogr 3:81-91
Brickman D, Frank KT (2000) Modelling the dispersal and mortality of Browns Bank egg and larval haddock (Melanogrammus aeglefinus). Can J Fish Aquat Sci 57:2519-2535

Brickman D, Smith PC (2002) Lagrangian stochastic modeling in coastal oceanography. J Atmos Ocean Technol 19:83-99

Brickman D, Shackell NL, Frank KT (2001) Modelling the retention and survival of Browns Bank haddock larvae using an early life stage model. Fish Oceanogr 10:284-296

Browman HI, St-Pierre JF, Skiftesvik AB, Racca RG (2006) Behaviour of Atlantic cod (Gadus morhua) larvae: an attempt to link maternal condition with larval quality. In: Browman HI, Skiftesvik AB (eds) The big fish bang: proceedings of the 26th annual larval fish conference. Institute of Marine Research, Bergen, p 71-95

Brown CA, Holt SA, Jackson GA, Brooks DA, Holt GJ (2004) Simulating larval supply to estuarine nursery areas: How important are physical processes to the supply of larvae to the Aransas Pass Inlet? Fish Oceanogr 13:181-196

Bruce BD, Condie SA, Sutton CA (2001) Larval distribution of blue grenadier (Macruronus novaezelandiae Hector) in south-eastern Australia: further evidence for a second spawning area. Mar Freshw Res 52:603-610

Bryan K (1969) A numerical model for the study of the circulation of the world ocean. J Phys Oceanogr 15:1312-1324

Bunnell DB, Miller TJ (2005) An individual-based modeling approach to per-recruit models: blue crab Callinectes sapidus in the Chesapeake Bay. Can J Fish Aquat Sci 62:2560-2572

Capella JE, Quetin LB, Hofman EE, Ross RM (1992) Models of the early life history of Euphausia superba-Part II. Lagrangian calculations. Deep-Sea Res 39:1201-1220

Cowan JH Jr, Shaw RF (2002) Recruitment. In: Fuiman LA, Werner RG (eds) Fishery science: the unique contribution of early life stages. Blackwell Science, Oxford, p 88-111

Cowan JH Jr, Rose KA, Rutherford ES, Houde ED (1993) Individual based model of young-of-the-year striped bass population dynamics. II. Factors affecting recruitment in the Potomac River, Maryland. Trans Am Fish Soc 122:439-458

Cowan JH Jr, Houde E, Rose K (1996) Size-dependent vulnerability of marine fish larvae to predation: an individualbased numerical experiment. ICES J Mar Sci 53:23-37

Cowen RK, Paris CB, Srinivasan A (2006) Scaling of connectivity in marine populations. Science 311:522-527

Cox MD (1984) A primitive equation 3-dimensional model of the ocean. Report No. 1, Princeton University Press, Princeton, NJ

Crowder L, Rice J, Miller T, Marschall E (1992) Empirical and theoretical approaches to size-based interactions and recruitment variability in fishes. In: Individual based models and approaches in ecology: populations, communities, and ecosystems. Chapman \& Hall, London, p 237-255

DeAngelis D, Gross L (1992) Individual based models and approaches in ecology: populations, communities, and ecosystems. Chapman \& Hall, London

DeAngelis D, Cox D, Coutant C (1980) Cannibalism and size dispersal in young-of-the-year largemouth bass: experiment and a model. Ecol Model 8:133-148

deYoung B, Heath M, Werner FE, Chai F, Megrey BA, Monfray P (2004) Challenges of modelling ocean basin ecosystems. Science 304:1463-1466

Fiksen Ø, MacKenzie BR (2002) Process-based models of feeding and prey selection in larval fish. Mar Ecol Prog Ser 243:151-164

Folkvord A (2005) Comparison of size-at-age of larval Atlantic cod (Gadus morhua) from different populations based on size- and temperature-dependent growth models. Can J Fish Aquat Sci 62:1037-1052

Friedrichs MAM, Hood RR, Wiggert JD (2006) Ecosystem 
model complexity versus physical forcing: quantification of their relative impact with assimilated Arabian Sea data. Deep-Sea Res Part II 53:576-600

Gallego A, Heath MR, Basfrod DJ, MacKenzie BR (1999) Variability in growth rates of larval haddock in the northern North Sea. Fish Oceanogr 8:77-92

Gentleman W (2002) A chronology of plankton dynamics in silico: how computer models have been used to study marine ecosystems. Hydrobiologia 480:69-85

Govoni JJ (2005) Fisheries oceanography and the ecology of early life histories of fishes: a perspective over fifty years. Sci Mar 69:125-137

Grimm V, Railsback SF (2005) Individual-based modeling and ecology. Princeton University Press, Princeton, NJ

Haidvogel DB, Beckman A (1998) Numerical modeling of the coastal ocean. In: Brink KH, Robinson AR (eds) The sea, Vol 10. Harvard University Press, Cambridge, MA, p 457-482

Hao W, Jian S, Ruijing W, Lei W, Yi'an L (2003) Tidal front and the convergens of anchovy (Engraulis japonicus) eggs in the Yellow Sea. Fish Oceanogr 12:434-442

Hare JA, Quinlan JA, Werner FE, Blanton BO, Govoni JJ, Forward RB Jr, Settle LR, Hoss DE (1999) Larval transport during winter in the SABRE study area: results of a coupled vertical larval behaviour-three-dimensional circulation model. Fish Oceanogr 8:57-76

Haury LR, McGowan JA, Wiebe PH (1978) Patterns and processes in the time-space scales of plankton distributions. In: Steele JH (ed) Spatial patterns in plankton communities. Plenum Press, New York, p 277-327

Heath MR, Gallego A (1997) From the biology of the individual to the dynamics of the population: bridging the gap in fish early life studies. J Fish Biol 51:1-29

Heath MR, Gallego A (1998) Biophysical modelling of the early life stages of haddock, Melanogrammus aeglefinus, in the North Sea. Fish Oceanogr 7:110-125

Heath M, Zenitani H, Watanabe Y, Kimura R, Ishida M (1998) Modelling the dispersal of larval Japanese sardine, Sardinops melanostictus, by the Kuroshio Current in 1993 and 1994. Fish Oceanogr 7:335-346

Helbig JA, Pepin P (2002) The effects of short space and time scale current variability on the predictability of passive ichthyoplankton distributions: an analysis based on HF radar observations. Fish Oceanogr 11:175-188

Hermann AJ, Rugen WC, Stabeno PJ, Bond NA (1996) Physical transport of young pollock larvae (Theragra chalcogramma) near Shelikof Strait as inferred from a hydrodynamic model. Fish Oceanogr 5:58-70

Hermann AJ, Hinckley S, Megrey BA, Napp JM (2001) Applied and theoretical considerations for structuring spatially explicit individual-based models of marine larval fish that include multiple trophic levels. ICES J Mar Sci 58:1030-1041

Hinckley S, Hermann AJ, Megrey BA (1996) Development of a spatially explicit, individual-based model of marine fish early life history. Mar Ecol Prog Ser 139:47-68

Hinckley S, Hermann AJ, Mier KL, Megrey BA (2001) Importance of spawning location and timing to successful transport to nursery areas: a simulation study of Gulf of Alaska walleye pollock. ICES J Mar Sci 58:1042-1052

Hinrichsen HH, Bottcher U, Oeberst R, Voss R, Lehmann A (2001) The potential for advective exchange of the early life stages between western and eastern Baltic cod (Gadus morhua). Fish Oceanogr 10:249-258

Hinrichsen HH, Mollmann C, Voss R, Koster FW, Kornilovs G (2002) Biophysical modeling of larval Baltic cod (Gadus morhua) growth and survival. Can J Fish Aquat Sci 59:
1858-1873

Hinrichsen HH, Bottcher U, Koster FW, Lehmann A, St John MA (2003a) Modelling the influences of atmospheric forcing conditions on Baltic cod early life stages: distribution and drift. J Sea Res 49:187-201

Hinrichsen HH, Lehmann A, Mollmann C, Schmidt JO (2003b) Dependency of larval fish survival on retention/dispersion in food limited environments: the Baltic Sea as a case study. Fish Oceanogr 12:425-433

Hinrichsen HH, Kraus G, Voss R, Stepputtis D, Baumann M (2005) The general distribution pattern and mixing probability of Baltic sprat juvenile populations. J Mar Syst 58:52-66

Hislop JRG, Gallego A, Heath MR, Kennedy FM, Reeves SA, Wright PJ (2001) A synthesis of the early life history of the anglerfish, Lophius piscatorius (Linnaeus, 1758) in northern British waters. ICES J Mar Sci 58:70-86

Hjort J (1914) Fluctuations in the great fisheries of northern Europe viewed in light of biological research. Rapp P-V Reun Cons Int Explor Mer 19:1-228

Houde E (1989) Subtleties and episodes in the early life of fishes. J Fish Biol 35:29-38

Huggett J, Fréon P, Mullon C, Penven P (2003) Modelling the transport success of anchovy Engraulis encrasicolus eggs and larvae in the southern Benguela: the effect of spatiotemporal spawning patterns. Mar Ecol Prog Ser 250: 247-262

Hutchings J (2000) Collapse and recovery of marine fishes. Nature 406:882-885

Ishizaka J, Hofman EE (1988) Plankton dynamics on the outer southeastern US continental shelf. Part I. Lagrangian particle tracing experiments. J Mar Res 46:853-882

Kingsland SE (1985) Modeling nature: episodes in the history of population dynamics. University of Chicago Press, Chicago, IL

Koster F, Hinrichsen HH, St John MA, Schnack D, MacKenzie BR, Tomkiewicz J, Plikshs M (2001) Developing Baltic cod recruitment models. II. Incorporation of environmental variability and species interaction. Can J Fish Aquat Sci 58:1534-1556

Laurence G (1978) Comparative growth, respiration and delayed feeding abilities of larval cod (Gadus morhua) and haddock (Melanogrammus aeglefinus) as influenced by temperature during laboratory studies. Mar Biol 50:1-7

Letcher B, Rice J, Crowder L, Rose K (1996) Variability in survival of larval fish: disentangling components with generalized individual-based models. Can J Fish Aquat Sci 53:787-801

Lomnicki A (1992) Population ecology from the individual perspective. In: Individual based models and approaches in ecology: populations, communities, and ecosystems. Chapman \& Hall, London, p 3-17

Lough RG, Manning JP (2001) Tidal-front entrainment and retention of fish larvae on the southern flank of Georges Bank. Deep-Sea Res 48:631-644

Lough RG, Buckley LJ, Werner FE, Quinlan JA, Edwards KP (2005) A general biophysical model of larval cod (Gadus morhua) growth applied to populations on Georges Bank. Fish Oceanogr 14:241-262

Lynch DR, Ip JTC, Naimie CE, Werner FE (1996) Comprehensive coastal circulation model with application to the Gulf of Maine. Cont Shelf Res 16:875-906

MacKenzie BR, Miller TJ, Cyr S, Leggett WC (1994) Evidence for a dome-shaped relationship between turbulence and larval fish ingestion rates. Limnol Oceanogr 39:1790-1799

Maes J, Limburg KE, Van de Putte A, Ollevier F (2005) A spatially explicit, individual-based model to assess the role of estuarine nurseries in the early life history of North Sea 
herring, Clupea harengus. Fish Oceanogr 14:17-31

Meekan MG, Fortier L (1996) Selection for fast growth during the larval life of Atlantic cod Gadus morhua on the Scotian Shelf. Mar Ecol Prog Ser 137:25-37

Megrey BA, Hinckley S (2001) Effect of turbulence on feeding of larval fishes: a sensitivity analysis using an individualbased model. ICES J Mar Sci 58:1015-1029

Megrey BA, Hinckley S, Dobbins EL (2002) Using scientific visualization tools to facilitate analysis of multi-dimensional data from a spatially explicit, biophysical, individualbased model of marine fish early life history. ICES J Mar Sci 59:203-215

Miller TJ, Crowder LB, Rice JA, Marschall EA (1988) Larval size and recruitment mechanisms in fishes: toward a conceptual framework. Can J Fish Aquat Sci 45:1657-1670

Mullon C, Cury P, Penven P (2002) Evolutionary individualbased model for the recruitment of anchovy (Engraulis capensis) in the southern Benguela. Can J Fish Aquat Sci 59:910-922

Mullon C, Fréon P, Parada C, Van Der Lingen C, Huggett J (2003) From particles to individuals: modelling the early stages of anchovy (Engraulis capensis/encrasicolus) in the southern Benguela. Fish Oceanogr 12:396-406

Myers RA (1995) Recruitment of marine fish: the relative roles of density-dependent and density-independent mortality in the egg, larval, and juvenile stages. Mar Ecol Prog Ser 128:308-309

North EW, Hood RR, Chao SY, Sanford LP (2005) The influence of episodic events on transport of striped bass eggs to the estuarine turbidity maximum nursery area. Estuaries 28:108-123

Paris CB, Cowen RK, Claro R, Lindeman KC (2005) Larval transport pathways from Cuban snapper (Lutjanidae) spawning aggregations based on biophysical modeling. Mar Ecol Prog Ser 296:93-106

Pedersen OP, Slagstad D, Tande KS (2003) Hydrodynamic model forecasts as a guide for process studies on plankton and larval fish. Fish Oceanogr 12:369-380

Quinlan JA, Blanton BO, Miller TJ, Werner FE (1999) From spawning grounds to the estuary: using linked individualbased and hydrodynamic models to interpret patterns and processes in the oceanic phase of Atlantic menhaden Brevoortia tyrannus life history. Fish Oceanogr 8(Suppl 2): 224-246

Reiss CS, Panteleev G, Taggart CT, Sheng J, deYoung B (2000) Observations on larval fish transport and retention on the Scotian Shelf in relation to geostrophic circulation. Fish Oceanogr 9:195-213

Rice J, Crowder L, Holey M (1987) Exploration of mechanisms regulating larval survival in Lake Michigan bloater: a recruitment analysis based on characteristics of individual larvae. Trans Am Fish Soc 116:703-718

Rice JA, Miller TJ, Rose KA, Crowder LB, Marschall EA, Trebitz AS, DeAngelis DL (1993) Growth rate variation and larval survival: inferences from an individual-based size-dependent population model. Can J Fish Aquat Sci 50:133-142

Rose KA, Cowan JH Jr (1993) Individual-based model of young-of-the-year striped bass population dynamics. I. Model description and baseline simulations. Trans Am Fish Soc 122:415-438

Rose KA, Cowan JH Jr, Clark ME, Houde ED, Wang SB (1999a) An individual-based model of bay anchovy population dynamics in the mesohaline region of Chesapeake Bay. Mar Ecol Prog Ser 185:113-132

Rose KA, Rutherford ES, McDermot DS, Forney JL, Mills EL (1999b) Individual-based model of yellow perch and walleye populations in Oneida Lake. Ecol Monogr 69:127-154

Rose KA, Murphy CA, Diamond SL, Fuiman L, Thomas P
(2003) Using nested models and laboratory data for pre dicting population effects of contaminants on fish: a step toward a bottom-up approach for establishing causality in field studies. Human Ecol Risk Assess 9:231-257

Sætre R, Toresen R, Soiland G, Fossum P (2002) The Norwegian spring-spawning herring - spawning, larval drift and larval retention. Sarsia 87:167-178

Scheffer M, Baveco JM, DeAngelis DL, Rose KA, van Nes EH (1995) Super-individuals: a simple solution for modelling large populations on an individual basis. Ecol Model 80: $161-170$

Shackell N, Frank K, Petrie B, Brickman D, Shore J (1999) Dispersal of early life stage haddock (Melanogrammus aeglefinus) as inferred from the spatial distribution and variability in length-at-age of juveniles. Can J Fish Aquat Sci 56:2350-2361

Stegmann PM, Quinlan JA, Werner FE, Blanton BO, Berrien P (1999) Atlantic menhaden recruitment to a southern estuary: defining potential spawning regions. Fish Oceanogr 8:111-123

Stenevik EK, Skogen M, Sundby S, Boyer D (2003) The effect of vertical and horizontal distribution on retention of sardine (Sardinops sagax) larvae in the northern Benguelaobservations and modelling. Fish Oceanogr 12:185-200

Suda M, Kishida T (2003) A spatial model of population dynamics of early life stages of Japanese sardine, Sardinops melanostictus, off the Pacific coast of Japan. Fish Oceanogr 12:85-99

Thorrold S, Latkoczy C, Swart P, Jones C (2001) Natal homing in a marine fish metapopulation. Science 291:297-299

Vikebø F, Sundby S, Adlandsvik B, Fiksen Ø (2005) The combined effect of transport and temperature on distribution and growth of larvae and pelagic juveniles of ArctoNorwegian cod. ICES J Mar Sci 62:1375-1386

Visser AW, Kiørboe T (2006) Plankton motility patterns and encounter rates. Oecologia 148:538-546

Voss R, Hinrichsen HH, St. John M (1999) Variations in the drift of larval cod (Gadus morhua L.) in the Baltic Sea: combining field observations and modelling. Fish Oceanogr 8:199-211

Weissburg MJ, Browman HI (eds) (2005) Sensory biology: linking the internal and external ecologies of marine organisms. Mar Ecol Prog Ser 287:263-307

Werner FE, Quinlan JA (2002) Fluctuations in marine fish populations: physical processes and numerical modelling. ICES Mar Sci Symp 215:264-278

Werner F, Page F, Lynch D, Loder J, Lough R, Perry R, Greenberg D, Sinclair M (1993) Influences of mean advection and simple behavior on the distribution of cod and haddock early life stages on Georges Bank. Fish Oceanogr 2:43-46

Werner FE, Perry RI, Lough RG, Lynch DR (1994) A coupled individual-based trophodynamics and circulation model for studies of larval cod and haddock on Georges Bank. US Globec News 7:1-8

Werner FE, Perry RI, MacKenzie BR, Lough GR, Naimie CE (1995) Larval trophodynamics, turbulence, and drift on Georges Bank: a sensitivity analysis of cod and haddock. ICES CM 1995/Q:26

Werner FE, Perry RI, Lough RG, Naimie CE (1996) Trophodynamic and advective influences on Georges Bank larval cod and haddock. Deep-Sea Res Part II 43:1793-1822

Werner FE, MacKenzie BR, Perry RI, Lough RG, Naimie CE, Blanton BO, Quinlan JA (2001a) Larval trophodynamics, turbulence, and drift on Georges Bank: a sensitivity analysis of cod and haddock. Sci Mar 65:99-115

Werner FE, Quinlan JA, Lough RG, Lynch DR (2001b) Spatiallyexplicit individual based modeling of marine populations: a review of the advances in the 1990s. Sarsia 86:411-421 